Supporting Information for

\title{
Au-Decorated N-Rich Carbon Dots as Peroxidase Mimics for Detection of Acetylcholinesterase Activity
}

\author{
Dingding Zhang ${ }^{a}$, Qingyi Han ${ }^{a}$, Wendong Liu ${ }^{a}$, Keying Xu ${ }^{a}$, Mingzheng Shao ${ }^{a}$, Yuyan $\mathrm{Li}^{a}$, \\ Peiyao Du ${ }^{a}$, Zhen Zhang ${ }^{a}$, Bingsi Liu ${ }^{a}$, Libing Zhang ${ }^{a}{ }^{*}$ and Xiaoquan Lu $^{b}{ }^{*}$ \\ a Tianjin Key Laboratory of Molecular Optoelectronic, Department of Chemistry, Tianjin University, \\ Tianjin 300072, People's Republic of China \\ ${ }^{b}$ Key Laboratory of Bioelectrochemistry and Environmental Analysis of Gansu Province, College of \\ Chemistry and Chemical Engineering, Northwest Normal University, Lanzhou 730070, People’s \\ Republic of China
}




\section{Materials, Instruments and Methods}

\section{Reagents and Materials.}

$\mathrm{HAuCl}_{4}$, polyethylene polyamine (PEPA), $\mathrm{CH}_{3} \mathrm{COOH}, \mathrm{CH}_{3} \mathrm{COONa}$, 1,2-diaminobenzene (OPD), 2,2'-azino-bis(3-ethylbenzothiazoline-6-sulfonic acid) (ABTS) were all purchased from Shanghai Aladdin Biochemical Technology Co., Ltd. Acetylcholinesterase (AChE), Acetylthiocholine chloride (ATCh) were purchased from Shanghai Maclin Biochemical Technology Co., Ltd. Sodium hydrogen phosphate dihydrate, sodium dihydrogen phosphate anhydrous were purchased from Sun Chemical Technology (Shanghai) Co., Ltd. 3,3',5,5'-tetramethylbenzidine (TMB) was obtained from Shanghai Adamas Reagent Co., Ltd. Ultrapure water ( $\geq 18 \mathrm{M} \Omega$, Millipore) was used in all experiments.

\section{Instrumentation.}

Transmission electron microscopy (TEM) measurements were made on a HITACHI H-8100 EM with an accelerating voltage of $200 \mathrm{kV}$. XPS measurement was performed on an ESCALAB-MKII spectrometer (VG Co., United Kingdom) with Al K $\alpha$ X-ray radiation as the X-ray source for excitation. Fourier infrared spectra (FTIR) were recorded on Nicolet is5 (Thermo, USA). UV-Vis data were measured on UV-3600PLUS UV-Vis-NIR spectrophotometer (Shimazu Corporation, Japan). ICP-MS measurements were performed on Agilent 725 (USA), ESR were performed on Broker-A200 (Germany).

\section{Synthesis of Cit-AuNPs (3 nm) and Cit-AuNPs (13 nm).}

Cit-Au NPs $(3 \mathrm{~nm}):{ }^{1} \mathrm{Au}$ nanoparticles were obtained through adding $0.972 \mathrm{~mL}$ of $1 \%$ aqueous $\mathrm{HAuCl}_{4}$ to $90 \mathrm{~mL}$ of $\mathrm{H}_{2} \mathrm{O}$ in an ice bath under vigorous stirring, and then $2 \mathrm{~mL}$ of $1 \%$ aqueous 
$\mathrm{Na}_{3}$-citrate was added after 1 minute. After that, $1 \mathrm{~mL}$ of $0.075 \% \mathrm{NaBH}_{4}$ in $1 \% \mathrm{Na}_{3}$-citrate was also added. The solution was stirred for another 5 minutes and then stored at $4{ }^{\circ} \mathrm{C}$. Thus the solution of $3 \mathrm{~nm}$-diameter particles was synthesized successfully.

Cit-Au NPs $(13 \mathrm{~nm}):{ }^{2}$ Briefly, a sodium citrate solution $(0.1 \mathrm{M}, 1.94 \mathrm{~mL})$ was rapidly added to a boiled $\mathrm{HAuCl}_{4}$ solution $\left(50 \mathrm{~mL} \mathrm{H} \mathrm{H}_{2} \mathrm{O}, 0.0167 \mathrm{~g} \mathrm{HAuCl}_{4}\right)$ with vigorous stirring. The mixed solution was boiled for $10 \mathrm{~min}$ and further stirred for $15 \mathrm{~min}$. The resulting wine-red solution was cooled to room temperature and filtered, which was stored in the $4{ }^{\circ} \mathrm{C}$ refrigerators before use.

\section{Recyclability assessment.}

$50 \mathrm{~mL} \mathrm{Au-CDs}\left(0.1 \mathrm{mg} \mathrm{mL}^{-1}\right), 50 \mathrm{~mL} \mathrm{H}_{2} \mathrm{O}_{2}$ and $50 \mathrm{~mL}$ TMB were added to $350 \mathrm{~mL}$ HAc-NaAc and reacted at $30{ }^{\circ} \mathrm{C}$ for $15 \mathrm{~min}$. Centrifuge the above-reacted solution at $14000 \mathrm{rpm}$ for $15 \mathrm{~min}$, discard the supernatant, and wash the bottom sediment with ultrapure water, redisperse the sediment in $50 \mathrm{~mL}$ of aqueous solution and perform the second test, and the subsequent steps are the same as above.

\section{Steady-state kinetic assay of the Au-CDs.}

Typically, $350 \mu \mathrm{L}$ of acetate buffer (10 mM, pH 5.0), $50 \mu \mathrm{L}$ of Au-CDs $\left(0.1 \mathrm{mg} \mathrm{mL}^{-1}\right), 50 \mu \mathrm{L} 200$ $\mathrm{mM} \mathrm{H} \mathrm{H}_{2}$, and $50 \mu \mathrm{L}$ of TMB $(0.1-4 \mathrm{mM})$ were mixed, followed by monitoring the reaction-time curves. Similarly, to obtain the kinetic data for $\mathrm{H}_{2} \mathrm{O}_{2}, 350 \mu \mathrm{L}$ of acetate buffer (10 mM, pH 5.0), 50 of $\mu \mathrm{L} \mathrm{Au-CDs}\left(0.1 \mathrm{mg} \mathrm{mL}^{-1}\right), 50 \mu \mathrm{L}$ of TMB $(4 \mathrm{mM})$ and $50 \mu \mathrm{L} \mathrm{H}_{2} \mathrm{O}_{2}(1-1000 \mathrm{mM})$ were mixed.

\section{Selectivity and anti-interference ability.}

According to the acetylcholinesterase activity detection procedure, AChE was replaced with 
different proteins to evaluate the selectivity of the sensing system, and other conditions remained the same. The activity of ALP and GOx is three times higher than AChE, the concentration of BSA is $0.1 \mathrm{mg} \mathrm{mL}^{-1}$, and the concentration of other proteins is $0.2 \mathrm{mM}$. The anti-interference ability of the sensor system was evaluated by adding $50 \mu \mathrm{L}$ different proteins into $30 \mu \mathrm{L}$ ATCh. 


\section{Tables and Figures}

Table S1. Au content in different solutions.

\begin{tabular}{cc}
\hline Sample & Au content (wt \%) \\
\hline Au-CD1 & 0.7 \\
Au-CDs2 & 2.1 \\
Au-CDs3 & 3.5 \\
Au-CDs4 & 4.7 \\
Au-CDs5 & 6.9 \\
Au NPs (3 nm) & 5.3 \\
AuNPs (13 nm) & 15.8 \\
\hline
\end{tabular}


Table S2. Catalytic Parameters comparison of Au-CDs , HRP, and different Au-based catalyst.

\begin{tabular}{|c|c|c|c|c|}
\hline Catalyst & Substrate & $\mathrm{K}_{\mathrm{m}}(\mathrm{mM})$ & $\mathrm{V}_{\max }\left(10^{-8} \mathrm{M} \cdot \mathrm{s}^{-1}\right)$ & Reference \\
\hline HRP & $\mathrm{H}_{2} \mathrm{O}_{2}$ & 3.7 & 8.71 & [3] \\
\hline HRP & TMB & 0.434 & 10 & [3] \\
\hline Tyr-Au NPs & $\mathrm{H}_{2} \mathrm{O}_{2}$ & 57.84 & 5.32 & {$[4]$} \\
\hline Tyr-Au NPs & TMB & 0.024 & 0.91 & [4] \\
\hline citrate-Au NPs & $\mathrm{H}_{2} \mathrm{O}_{2}$ & 61.34 & 0.663 & {$[5]$} \\
\hline citrate-Au NPs & TMB & 0.11 & 1.539 & {$[5]$} \\
\hline D-His@Au NCs & $\mathrm{H}_{2} \mathrm{O}_{2}$ & 72 & 5.55 & {$[6]$} \\
\hline D-His@Au NCs & TMB & 0.41 & 7.69 & {$[6]$} \\
\hline BSA-Au NCs & $\mathrm{H}_{2} \mathrm{O}_{2}$ & 16.71 & 1.302 & [7] \\
\hline BSA-Au NCs & TMB & 3.59 & 0.861 & {$[7]$} \\
\hline Au hydrogel & $\mathrm{H}_{2} \mathrm{O}_{2}$ & 19.92 & 12.8 & {$[8]$} \\
\hline Au hydrogel & TMB & 0.32 & 12.30 & {$[8]$} \\
\hline $\begin{array}{c}\text { ZnSA-AuAMP } \\
\text { hydrogel }\end{array}$ & $\mathrm{H}_{2} \mathrm{O}_{2}$ & 30.53 & 1.679 & [9] \\
\hline $\begin{array}{l}\text { ZnSA-AuAMP } \\
\text { hydrogel }\end{array}$ & TMB & 0.36 & 1.197 & [9] \\
\hline $\mathrm{Au}-\mathrm{CDs}$ & $\mathrm{H}_{2} \mathrm{O}_{2}$ & 34.76 & 7.95 & this work \\
\hline $\mathrm{Au}-\mathrm{CDs}$ & TMB & 0.0196 & 1.282 & this work \\
\hline
\end{tabular}


Table S3. Comparison of nanozyme-based biosensors for AChE detection.

\begin{tabular}{|c|c|c|c|c|}
\hline Nanozymes & Method & $\begin{array}{c}\text { Linear range }(\mathrm{mU} \\
\left.\mathrm{mL}^{-1}\right)\end{array}$ & $\begin{array}{c}\mathrm{LOD}(\mathrm{mU} \\
\left.\mathrm{mL}^{-1}\right)\end{array}$ & References \\
\hline $\mathrm{PAA}-\mathrm{CeO}_{2}$ & Fluorescence & $0.263-50$ & 0.263 & {$[10]$} \\
\hline Au@PDA NPs & Colormetric & $2.5-25$ & 0.9 & [11] \\
\hline RhB-p-SC ${ }_{6} \mathrm{~A}-\mathrm{AuNPs}$ & Fluorescence & $0-1.6$ & 0.16 & [12] \\
\hline Citrate- $\mathrm{CeO}_{2}$ & Colormetric & $0-1400$ & 3.5 & [13] \\
\hline RhB-p-SC ${ }_{6} \mathrm{~A}-\mathrm{AuNPs}$ & Colormetric & $0-5$ & 0.46 & [12] \\
\hline $\mathrm{NO}_{2}-\mathrm{MIL}-101$ & Colormetric & $0.2-50$ & 0.14 & [14] \\
\hline $\mathrm{Fe}-\mathrm{SAs} / \mathrm{NC}$ & Colormetric & $2-70$ & 0.56 & [15] \\
\hline PdSP@rGO & Colormetric & $0.25-5.0$ & 0.06 & [16] \\
\hline \multirow[t]{3}{*}{$\mathrm{Au}-\mathrm{CDs}$} & Colormetric & $0.1-5$ & 0.107 & This work \\
\hline & & $0.6-10$ & 0.157 & \\
\hline & & $1-17.5$ & 0.192 & \\
\hline
\end{tabular}




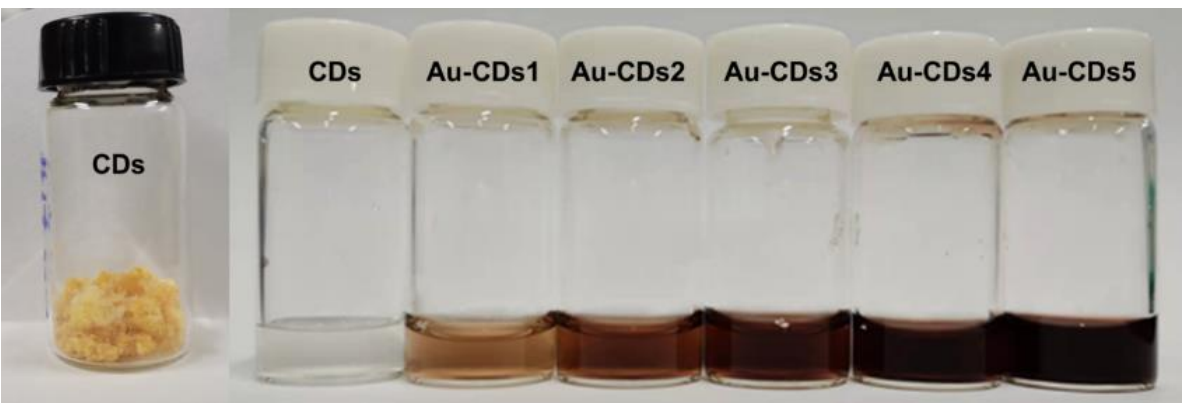

Figure S1. The digital photos of different products. The color of carbon dots and different Au-CDs solutions. 


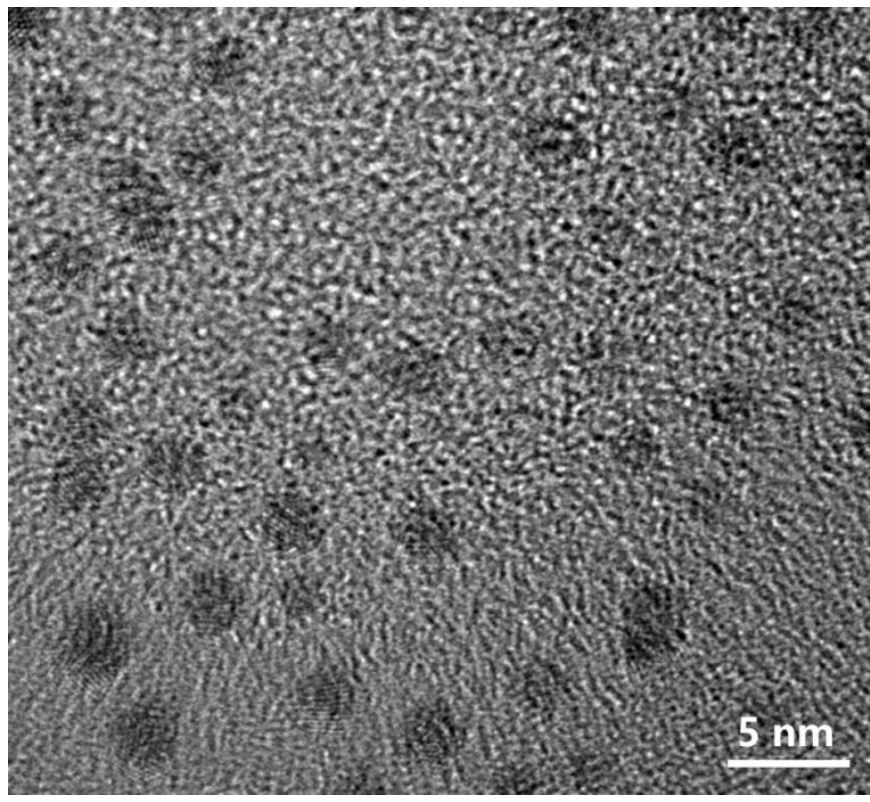

Figure S2. TEM image of Au-CDs stored at $4^{\circ} \mathrm{C}$ for one month. 


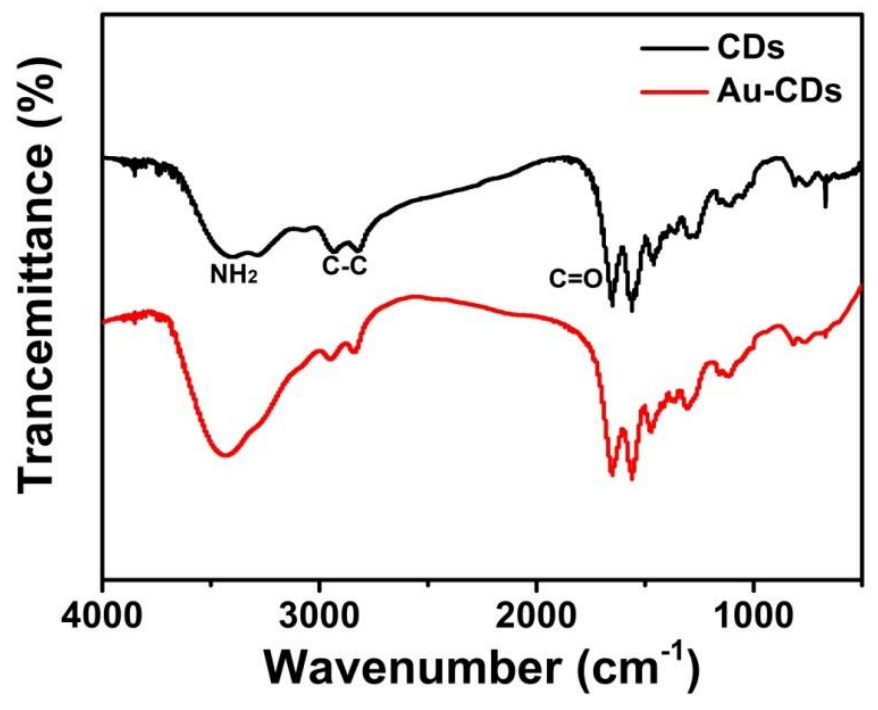

Figure S3. FTIR spectra of CDs and Au-CDs. 

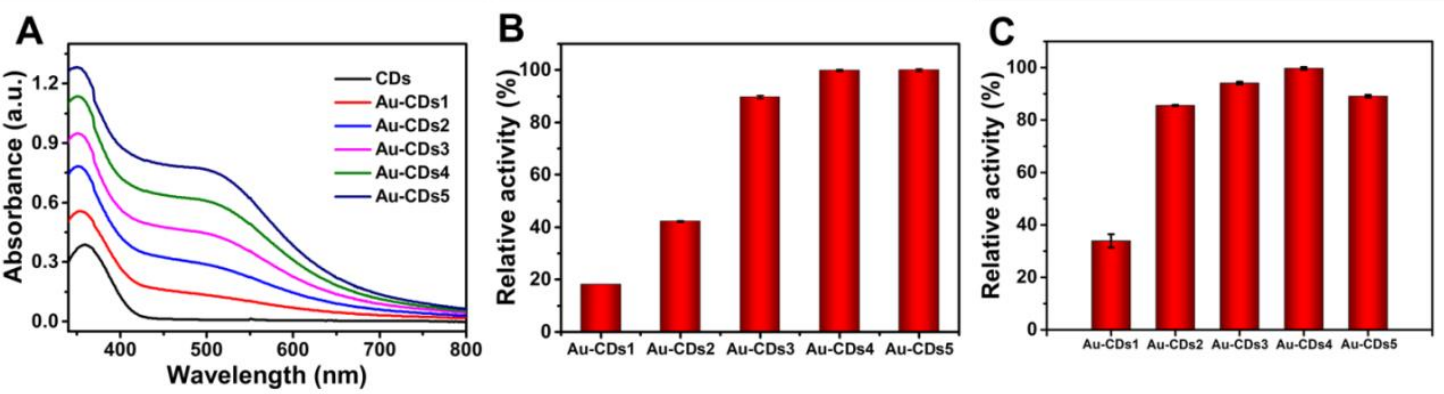

Figure S4. UV-vis spectra and relative activity of Au-CDs with different Au mass loadings. A) The UV-vis absorption of CDs and Au-CDs with different Au loadings; B) Relative activity of Au-CDs with different Au loadings for catalytic oxidation of TMB. C) Relative activity of different Au-CDs solutions with the same Au content for catalytic oxidation of TMB. 

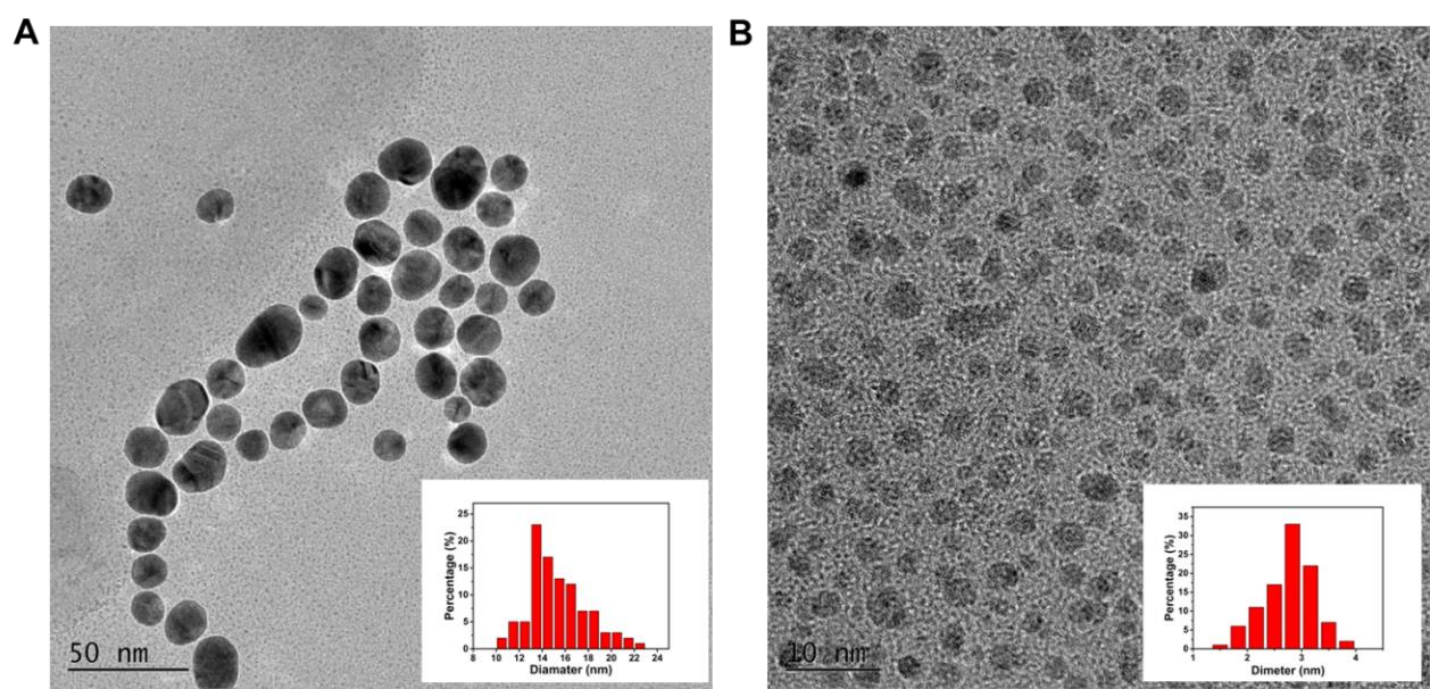

Figure S5. TEM images of Cit-Au NPs with different sizes. A) Cit-Au NPs $\mathrm{s}_{(13 \mathrm{~nm})}$ and B) Cit-Au $\mathrm{NPs}_{(3 \mathrm{~nm})}$. 

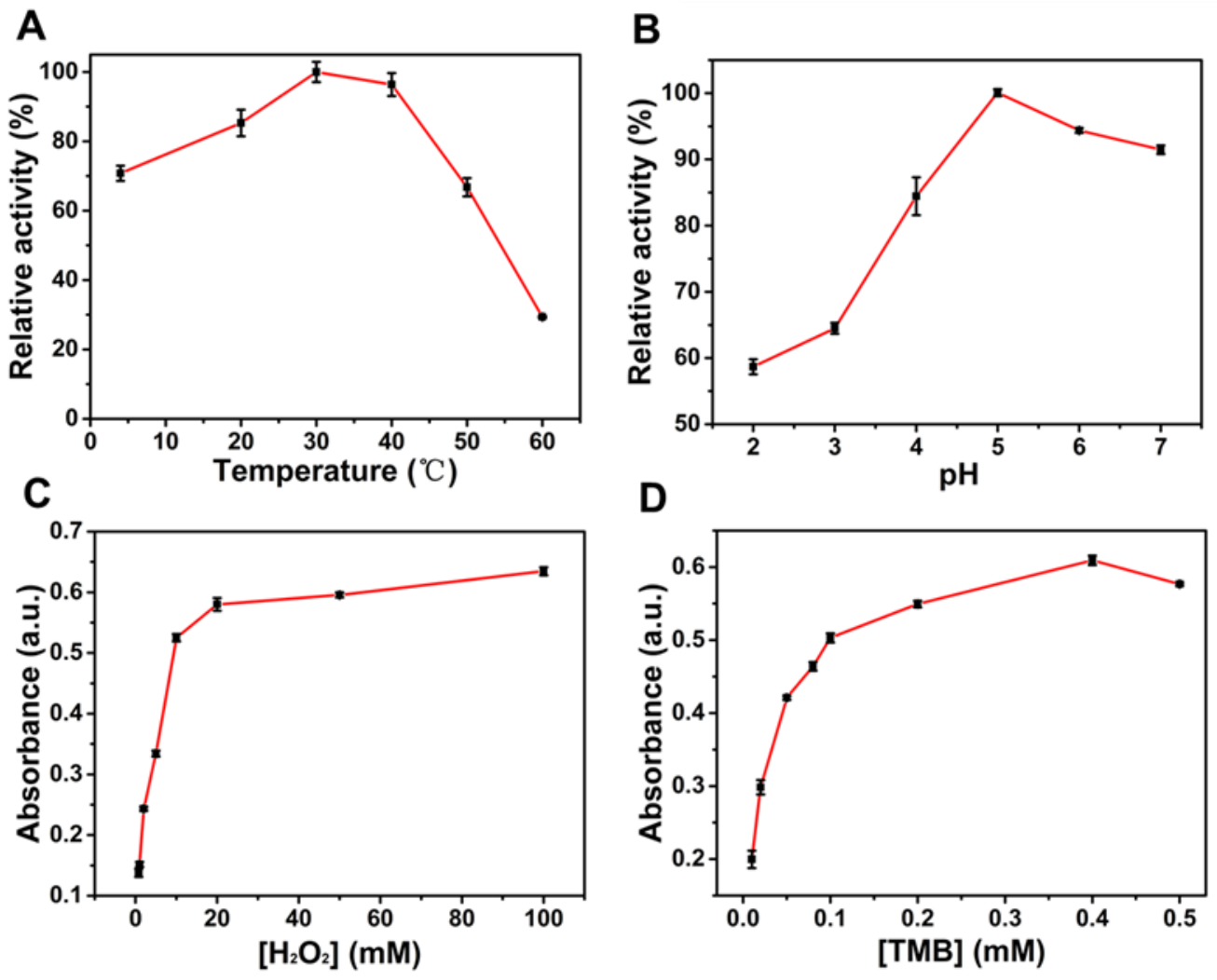

Figure S6. Optimization of Au-CDs reaction conditions. Peroxidase mimic activity of Au-CDs under different reaction conditions. A) reaction temperature; B) reaction system $\mathrm{pH}$; C, D) concentration of $\mathrm{H}_{2} \mathrm{O}_{2}$ and TMB, respectively. 

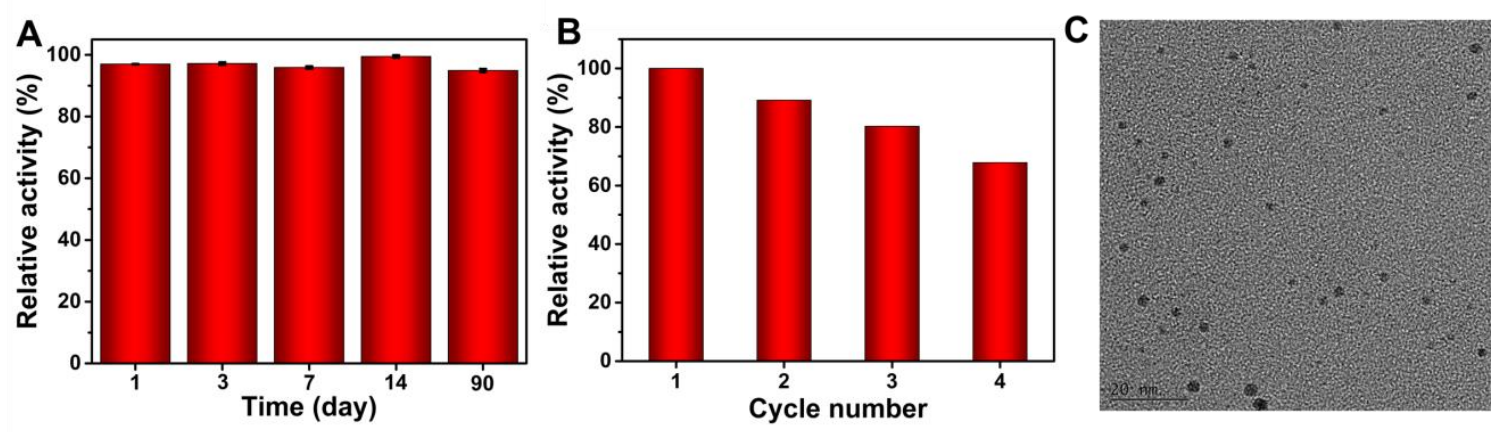

Figure S7. The stability and reusability of Au-CDs. A) The relative activity of Au-CDs at different storage times for catalytic oxidation of TMB. B) Cycle numbers of Au-CDs. C) TEM images of Au-CDs reacted with TMB and $\mathrm{H}_{2} \mathrm{O}_{2}$. 

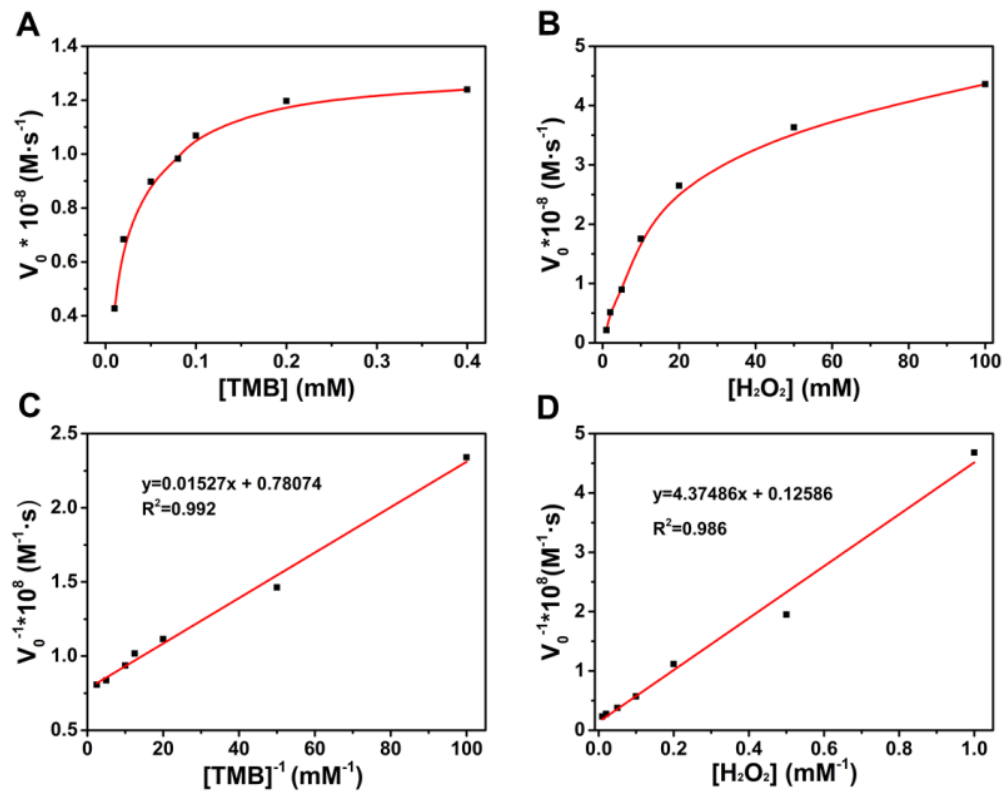

Figure S8. Kinetic analysis of $\mathrm{Au}-\mathrm{CDs}$ with $\mathrm{TMB}$ and $\mathrm{H}_{2} \mathrm{O}_{2}$ as substrates. Michaelis-Menten curves fit of A) TMB with a fixed concentration of $\mathrm{H}_{2} \mathrm{O}_{2}(20 \mathrm{mM})$, B) $\mathrm{H}_{2} \mathrm{O}_{2}$ with a fixed concentration of TMB (0.4 mM). The Lineweaver-Burk plots for C) TMB and D) $\mathrm{H}_{2} \mathrm{O}_{2}$. 


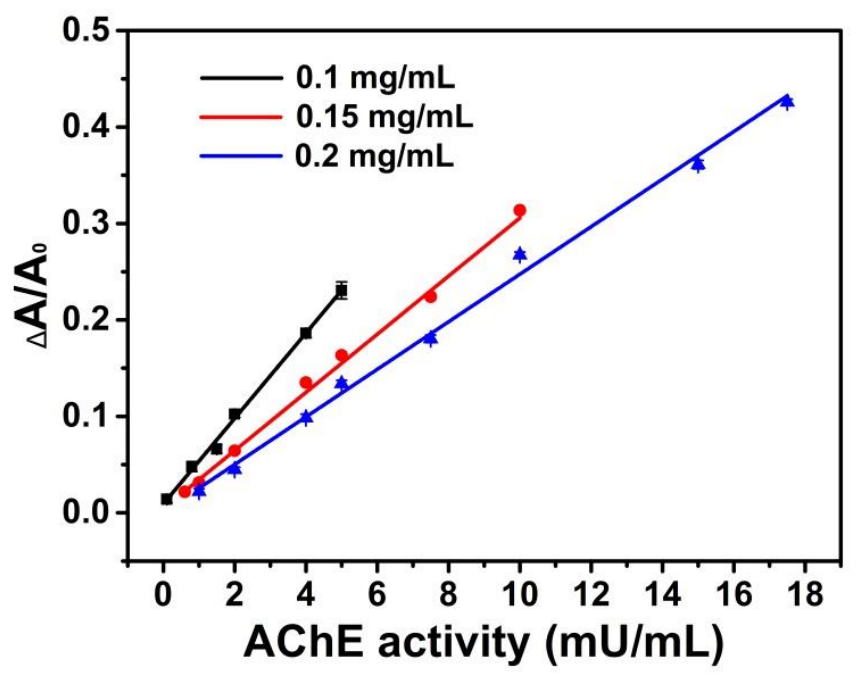

Figure S9. The linear response of $\mathrm{Au}-\mathrm{CDs}$ to $\mathrm{AChE}$ at different concentration. The signal corresponds to the increase of AChE concentration. (The linear response of the sensing platform in the presence of increasing concentration of $\mathrm{AChE}$, using three independent Au-CDs concentrations, respectively.) 


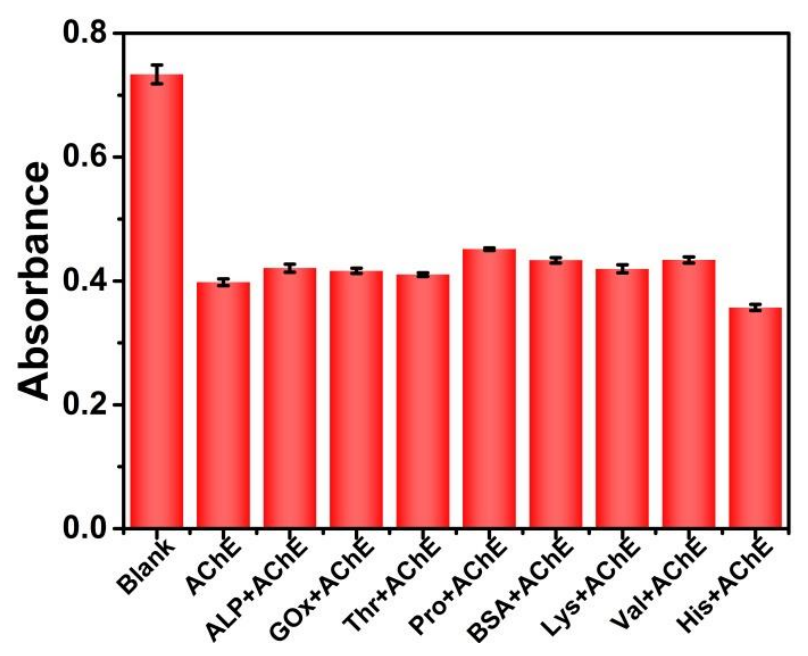

Figure S10. The anti-interference ability of Au-CDs for AChE detection. 


\section{References}

[1] Xiao, X.-Y.; Chen, S.-H.; Li, S.-S.; Wang, J.; Zhou, W.-Y.; Huang, X.-J. Synergistic Catalysis of N Vacancies and $\sim 5 \mathrm{~nm}$ Au Nanoparticles Promoted the Highly Sensitive Electrochemical Determination of Lead(II) Using an Au/N-Deficient- $\mathrm{C}_{3} \mathrm{~N}_{4}$ Nanocomposite. Environ Sci-Nano. 2019, 6, 1895-1908.

[2] Zhang, L.; Jean, S. R.; Li, X.; Sack, T.; Wang, Z.; Ahmed, S.; Chan, G.; Das, J.; Zaragoza, A.; Sargent, E.H.; Kelley, S.O. Programmable Metal/Semiconductor Nanostructures for mRNA-Modulated Molecular Delivery. Nano Lett. 2018, 18, $6222-6228$.

[3] Gao, L.; Zhuang, J.; Nie, L.; Zhang, J.; Zhang, Y.; Gu, N.; Wang, T.; Feng, J.; Yang, D.; Perrett, S.; Yan, X. Intrinsic Peroxidase-Like Activity of Ferromagnetic Nanoparticles. Nat. Nanotechnol. 2007, 2, 577-583.

[4] Weerathunge, P.; Ramanathan, R.; Torok, V.A.; Hodgson, K.; Xu, Y.; Goodacre, R.; Behera, B. K.; Bansal, V. Ultrasensitive Colorimetric Detection of Murine Norovirus Using NanoZyme Aptasensor. Anal Chem. 2019, 91, 3270-3276.

[5] Xue, Q.; Niu, X.; Liu, P.; Wang, M.; Peng, Y.; Peng, H.; Li, X. Analyte-Triggered Citrate-Stabilized Au Nanoparticle Aggregation with Accelerated Peroxidase-Mimicking Activity for Catalysis-Based Colorimetric Sensing of Arsenite. Sens Actuators B Chem. 2021, 334, 129650.

[6] Song, Y.; Qiao, J.; Liu, W.; Qi, L. Colorimetric Detection of Serum Doxycycline with D-histidine-Functionalized Gold Nanoclusters as Nanozymes. Analyst 2020, 145, 3564-3568.

[7] Hu, L.; Liao, H.; Feng, L.; Wang, M.; Fu, W. Accelerating the Peroxidase-Like Activity of Gold Nanoclusters at Neutral pH for Colorimetric Detection of Heparin and Heparinase Activity. Anal. Chem. 2018, 90, 6247-6252. 
[8] Jiao, L.; Xu, W.; Yan, H.; Wu, Y.; Gu, W.; Li, H.; Du, D.; Lin, Y.; Zhu, C. A Dopamine-Induced Au Hydrogel Nanozyme for Enhanced Biomimetic Catalysis. Chem Commun (Camb). 2019, 55, 9865-9868.

[9] Liu, L.; Jiang, H.; Wang, X. Alkaline Phosphatase-Responsive $\mathrm{Zn}^{2+}$ Double-Triggered Nucleotide Capped Gold Nanoclusters/ Alginate Hydrogel with Recyclable Nanozyme Capability. Biosens. Bioelectron. 2021, 173, 112786.

[10]Zhang, S. -X.; Xue, S. -F.; Deng, J.; Zhang, M.; Shi, G.; Zhou, T. Polyacrylic Acid-Coated Cerium Oxide Nanoparticles: An Oxidase Mimic Applied for Colorimetric Assay to Organophosphorus Pesticides. Biosens. Bioelectron. 2016, 85, 457-463.

[11] Zhang, J.; Mou, L.; Jiang, X. Hydrogels Incorporating Au@Polydopamine Nanoparticles: Robust Performance for Optical Sensing. Anal. Chem. 2018, 90, 11423-11430.

[12] Lv, J.; He, B.; Wang, N.; Li, M.; Lin, Y. A Gold Nanoparticle Based Colorimetric and Fluorescent Dual-Channel Probe for Acetylcholinesterase Detection and Inhibitor Screening. RSC Adv. 2018, 8, 32893-32898.

[13]Cheng, H.; Lin, S.; Muhammad, F.; Lin, Y.-W.; Wei, H. Rationally Modulate the Oxidase-like Activity of Nanoceria for Self-Regulated Bioassays. ACS Sens. 2016, 1, 1336-1343.

[14] Xu, W.; Kang, Y.; Jiao, L.; Wu, Y.; Yan, H.; Li, J.; Gu, W.; Song, W.; Zhu, C. Tuning Atomically Dispersed $\mathrm{Fe}$ Sites in Metal-Organic Frameworks Boosts Peroxidase-Like Activity for Sensitive Biosensing. Nano-Micro Lett. 2020, 12, 184.

[15]Wang, M.; Liu, L.; Xie, X.; Zhou, X.; Lin, Z.; Su, X. Single-Atom Iron Containing Nanozyme with Peroxidase-Like Activity and Copper Nanoclusters Based Ratio Fluorescent Strategy for Acetylcholinesterase Activity Sensing. Sens Actuators B Chem. 2020, 313, 128023 .

[16] Yan, B.; Liu, W.; Duan, G.; Ni, P.; Jiang, Y.; Zhang, C.; Wang, B.; Lu, Y.; Chen, C. Colorimetric Detection of Acetylcholinesterase and its Inhibitor based on 
Thiol-Regulated Oxidase-Like Activity of 2D Palladium Square Nanoplates on Reduced Graphene Oxide. Microchim Acta. 2021, 188, 162. 